\title{
3D printing-assisted interphase engineering of polymer composites: Concept and feasibility
}

\author{
G. Szebényi ${ }^{1,2}$, T. Czigány ${ }^{1,2}$, B. Magyar ${ }^{1}$, J. Karger-Kocsis ${ }^{1 *}$ \\ ${ }^{1}$ Department of Polymer Engineering, Faculty of Mechanical Engineering, Budapest University of Technology and \\ Economics, Muegyetem rkp. 3., H-1111 Budapest, Hungary \\ ${ }^{2}$ MTA-BME Research Group for Composite Science and Technology, Muegyetem rkp. 3., H-1111 Budapest, Hungary
}

Received 2 March 2017; accepted in revised form 31 March 2017

\begin{abstract}
We introduced a general concept to create smart, (multi)functional interphases in polymer composites with layered reinforcements, making use of 3D printing. The concept can be adapted for both thermoplastic and thermoset matrix-based composites with either thermoplastic- or thermoset-enriched interphases. We showed feasibility using an example of a composite containing a thermoset matrix/thermoplastic interphase. Carbon fiber unidirectional reinforcing layers were patterned with poly( $\varepsilon$-caprolactone) (PCL) through 3D printing, then infiltrated with an amine-cured epoxy (EP). The corresponding composites were subjected to static and dynamic flexure tests. The PCL-rich interphase markedly improved the ductility in static tests without deteriorating the flexural properties. Its effect was marginal in Charpy impact tests, which can be explained with effects of specimen and PCL pattern sizes. The PCL-rich interphase ensured self-healing when triggered by heat treatment above the melting temperature of PCL.
\end{abstract}

Keywords: concept, interphase, smart composites, reaction-induced phase separation, 3D printing

\section{Introduction}

Interphase has a key role when tailoring the performance of composite materials. Stress transfer from the 'weak' matrix to the 'strong' reinforcement via the interphase has a great effect not only on the strength but also on the toughness of the corresponding composites. Moreover, nowadays great efforts are devoted to create composites with a smart interphase. In such cases, the interphase ensures functional properties, such as electric conductivity, shape memory, self-healing, and the like [1]. The present research trend is to focus on the interphase rather than on the bulk modification of polymeric composites. In this respect it can be felt that 3D printing may have a crucial role in interphase engineering, especially when toughening and (multi)functionality are targeted. Some 'why' and 'how' aspects of interphase engineering through $3 \mathrm{D}$ printing are introduced next.
Polymer composites with layered reinforcements (unidirectional (UD), quasi-UD, bidirectional, woven, non-woven etc.) have outstanding mechanical performance in-plane by contrast to out-of-plane type loading [2]. To improve the latter, various approaches have been proposed (needling, stitching, pinning, interleaving etc.) and tried. There is a renewed interest in some of these strategies due to the appearance of novel techniques (e.g. electrospinning) and materials (self-healable ones). Thin electrospun nanolayers are incorporated to improve the interlaminar and interlayer properties of advanced composites without jeopardizing in-plane properties [3]. Self-healable interleaves may ensure the restoration of the property profile [4].

Thermosets, such as epoxy resins (EP), are often modified with thermoplastics to improve their toughness without seriously affecting their glass transition 
temperature $\left(T_{\mathrm{g}}\right)$. A great variety of amorphous and semicrystalline thermoplastics have already been used as potential tougheners [5]. They were incorporated as preformed particles or dissolved in the EP resin or hardener. In the latter case the preferred morphology in the EP matrix was achieved via reactioninduced phase separation (RIPS). RIPS itself depends on many parameters (the reactivity and molecular weight of the thermoplastic, the type of the EP and its hardener, crosslinking conditions etc.) and thus to set the desired morphology is challenging. Nanofillers may affect the RIPS, thereby offering a further tool for morphology control. This has been shown for example in $\mathrm{EP} /$ poly ( $\varepsilon$-caprolactone) (PCL) blends, modified with clays [6]. The other widely followed strategy is to use reactive thermoplastics the functional groups of which may react with those of the $\mathrm{EP}$ or its hardener. Note that PCL is a reactive thermoplastic modifier for EP in this respect.

EP systems, however, may also show functional properties, such as shape memory (SM) and self-healing. All EPs exhibit dual SM, that is, they can 'memorize' a temporary shape. The reversible 'switch' for that is given by the $T_{\mathrm{g}}$. The crosslinked network structure is responsible for the restoration of the initial shape. EP/PCL systems with a bicontinuous structure may show triple-shape behavior, i.e. capable of memorizing two temporary shapes. The related switches are the $T_{\mathrm{g}}$ of EP and the melting temperature $\left(T_{\mathrm{m}}\right)$ of the PCL. Note that the $T_{\mathrm{m}}$ of PCL is about $60^{\circ} \mathrm{C}$. In this case the intermingled, bicontinuous phase guarantees the recovery of the initial shape. Bicontinuity is achieved either by resin infiltration of a PCL nanoweb (produced for example through electrospinning $[7,8]$ or by RIPS when the PCL content is high enough [8]). The related structure can be termed as quasi (with the nanoweb) or real semi-interpenetrating network (semi-IPN) because the thermoplastic phase is also continuous.

It was also reported that thermoplastic PCL may work as a healing agent in EPs [9]. Healing occurs via chain entanglement of the PCL molecules above the $T_{\mathrm{m}}$. Not surprisingly, semi-IPN structured EP/PCL outperformed EP variants with dispersed PCL phase with respect to healing [9]. Note that all the above information is related to $\mathrm{EP} / \mathrm{PCL}$ modified in the bulk. The question arises: How can the related knowledge be transferred to the interphase? How can we produce a morphology-tailored interphase thereby triggering toughening and multifunctionality (selfhealing, shape memory, electric or magnetic conductivity etc.)? 3D printing is the right tool, as will be outlined next.

PCL can be fuse-deposited on the surface of reinforcing fabrics in different patterns - cf. Figure 1. Afterward, the reinforcing structure may be infiltrated by EP with the use of hand lay-up or different resin transfer molding techniques. During infiltration and following curing the deposited PCL may be partly or fully dissolved. However, even in the latter case PCL, being under constrains, remains in the interphase after RIPS, therefore a PCL-rich interphase develops. This PCL-rich interphase should work for toughness (interlaminar and interlayer) enhancement along with self-healing above the $T_{\mathrm{m}}$ of PCL. The PCL wire may contain various nanofillers (magnetite, carbon nanotubes, graphene etc.) to provide the interphase with additional properties such as magnetic or electrical conductivity.

The patterning itself is a further key parameter of performance control. Here is an example to highlight this aspect: equidistant unidirectional line deposition of PCL in consecutive reinforcing layers at angles of $\pm 45^{\circ}$ may enhance ductility (shear prone microstructuring)
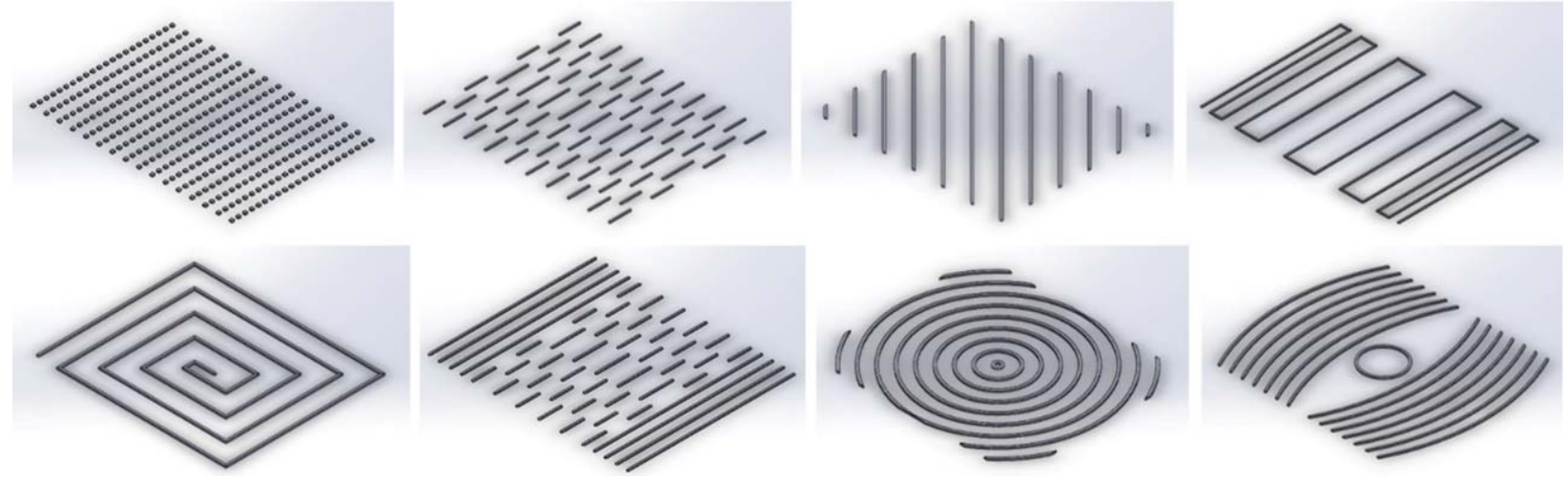

Figure 1. Some patterning options of $2 \mathrm{D}$ reinforcements through $3 \mathrm{D}$ printing 
- cf. Figure 1. Moreover, right patterning may contribute to a relieving of stress in stress concentration sites, which can happen in many ways (insert, hole - as depicted in Figure 1).

The critical fiber length in EPs is in the submillimeter range. Provided that the distance of the deposited PCL and its width are comparable with that of the actual critical fiber length, an old dream of scientist can be realized. Atkins recommended the intermittent bonded interphase concept in the 1970s [10] to improve the toughness of unidirectional fiber-reinforced advanced composites. The basic concept was to create a fiber surface with alternating sizing/nonsizing, which causes bonding/no bonding to the matrix. An inverse version of this concept (i.e. from the matrix side instead of the fiber) was proposed by Karger-Kocsis et al. [1] via the generation of a suitable IPN structure later.

3D patterning of the reinforcement may be associated with further benefits, such as better draping, creasing of the reinforcement - even during molding. The patterning for this purpose may well be supported by origami/kirigami knowledge.

The feasibility of the concept will be shown next with the example of CF-reinforced EP, the reinforcing layers of which were patterned with PCL wire in 3D printing, which represents a thermoset/thermoplastic combination. This 3D printing-assisted interphase engineering, however, can also be used for thermoplastic/thermoplastic and thermoset/thermoset pairs, as well. One of the most important aspects is that the deposited polymer giving the interphase should have

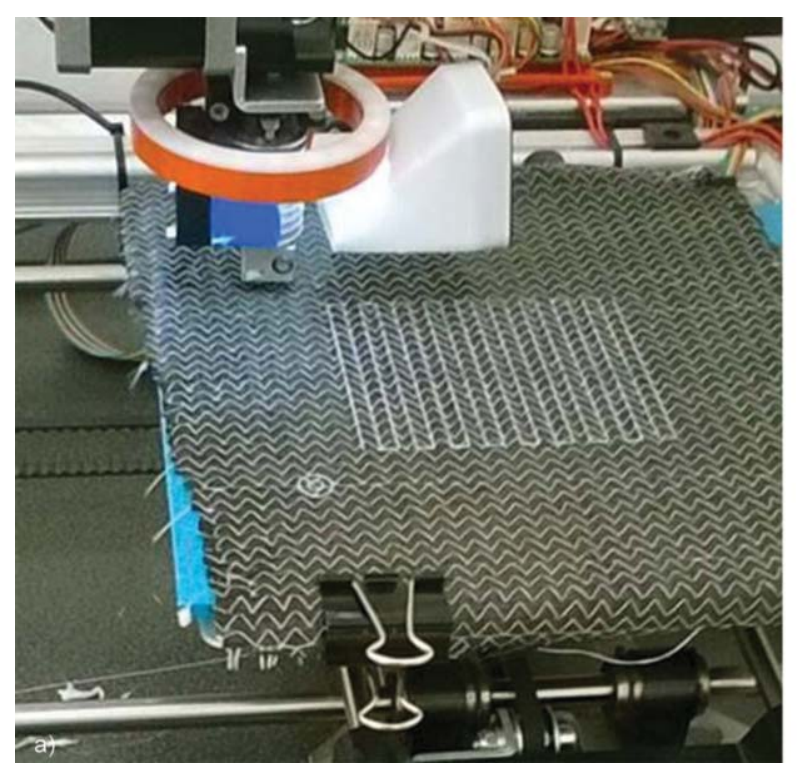

good bonding (via whatever interaction) to the matrix during the preparation/manufacturing process. For a thermoplastic/thermoplastic combination the vast knowledge with the related blends, while for thermoset/thermoset pairing knowledge gained on hybrid resins, and especially on consecutive IPN structured ones, should be considered as guide lines.

\section{Experimental}

\subsection{Materials}

IPOX ER 1010 (IPOX Chemicals Kft., Budapest, Hungary) DGEBA-based epoxy resin with IPOX MH 3124 amine-based curing agent was used as the matrix of the composite laminates. The mixing weight ratio was 100:35 according to the producer's specifications. The room temperature curing of this EP yields a glass transition temperature of about $80^{\circ} \mathrm{C}$. As fiber reinforcement PX35FBUD0300 (Zoltek Zrt., Nergesújfalu, Hungary) unidirectional carbon weave (surface weight $309 \mathrm{~g} / \mathrm{m}^{2}$ ), consisting of Panex35 $50 \mathrm{k}$ rovings was used.

For the 3D printed interface eMorph175N05 (Shenzhen Esun Industrial Co. Ltd., Shenzhen, China) PCL filament with a diameter of $1.75 \mathrm{~mm}$ was used (melting temperature, $T_{\mathrm{m}} \approx 60^{\circ} \mathrm{C}$, print temperature: $\left.>80^{\circ} \mathrm{C}\right)$.

\subsection{Creation of the interfacial pattern}

The interfacial pattern was created by fused deposition modeling (FDM) 3D printing with a customized Velleman K8200 (Velleman nv., Gavere, Belgium) $3 \mathrm{D}$ printer. The previously cut reinforcing layers were

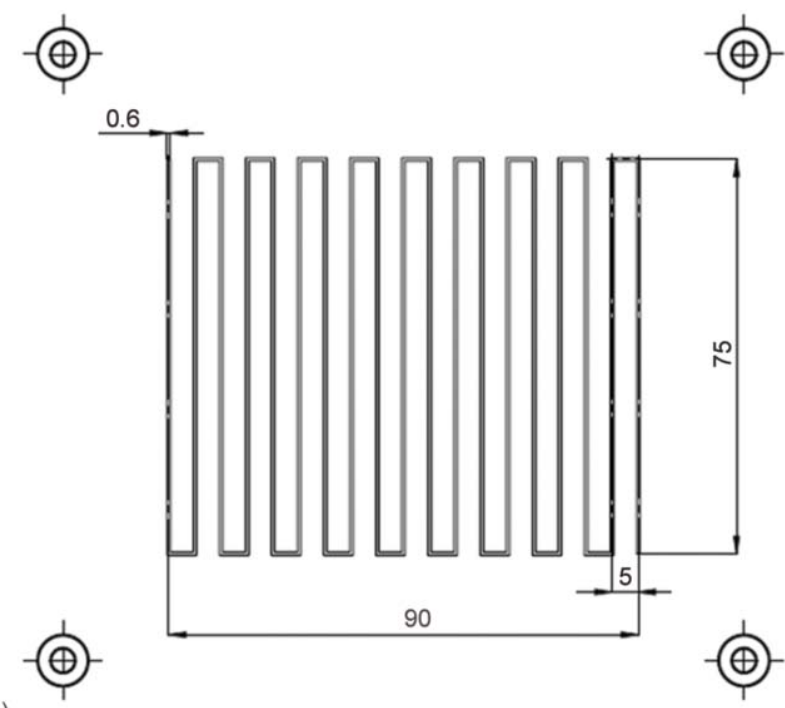

Figure 2. The setup of the interlaminar patterning by FDM 3D printing (a) and the pattern designed (dimensions in mm) (b) 
placed on the print bed of the 3D printer with the fiber direction parallel to its main movement axis and printed on one side (upper surface). A pattern consisting of double filaments with $5 \mathrm{~mm}$ spacing (Figure 2) was printed on the reinforcement layer surface with the previously optimized $180^{\circ} \mathrm{C}$ printing nozzle temperature and $40^{\circ} \mathrm{C}$ print bed temperature. The concentric circles were printed as markers to make the further alignment of the individual reinforcing layers easier. Via the pattern in Figure 2 intermittent bonding was targeted but it was not optimized with respect of any mechanical loading.

\subsection{Preparation of the composites}

The six-layer unidirectional composites were created by hand layup followed by vacuum pressing. The reinforcing layers were impregnated with the EP resin with peel plies on both the top and bottom layers to ease removal from the PET film that covered the glass sheet mold. A vacuum bag was built over the laminate to provide uniform pressing and a high fiber content ratio. A vacuum of 0.5 bar was applied for 1 hour during room temperature curing. In the case of interlaminar-patterned samples 5 patterned and 1 neat layer was laid up in a way that the patterns were present in all interlayers. It should be borne in mind that under this condition PCL is only partly dissolved in the EP. The laminate thickness of the CF/EP composite was $2.9 \mathrm{~mm}$, the thickness of the $\mathrm{CF} / \mathrm{EP}$ composite with the PCL interphase was $3.3 \mathrm{~mm}$. The specimens were cut from the laminates by a Mutronic Diadisc diamond disc saw according to the standard specifications.

\section{Results and discussion}

We investigated the increase in ductility of the prepared interlaminar-patterned composites in static and dynamic flexure tests. We preferred flexural tests because not only tensile and compressive, but also significant interlaminar loads are present during the fracture of specimens. The three-point bending tests were performed on standard $100 \mathrm{~mm}$ long, $15 \mathrm{~mm}$ wide specimens with a Zwick Z020 computer-controlled universal tester according to EN ISO 14125

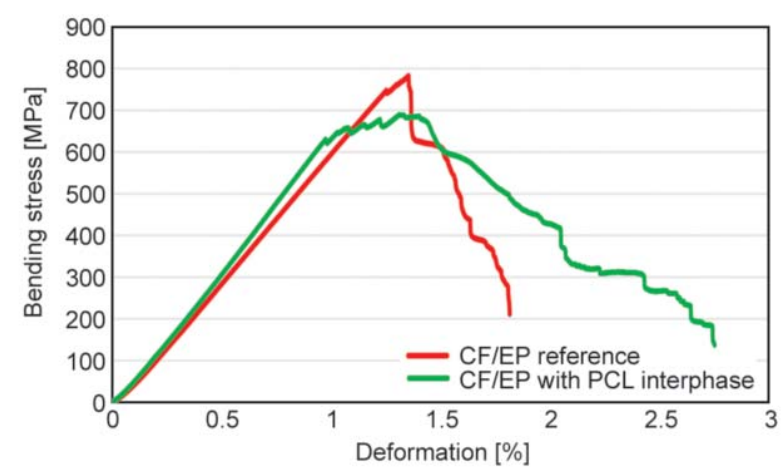

Figure 3. Characteristic bending stress-deformation curves in static three-point bending tests of the $\mathrm{CF} / \mathrm{EP}$ composites with and without a PCL-modified interphase

at room temperature. The tests were performed with $80 \mathrm{~mm}$ support span and at a test speed of $2 \mathrm{~mm} / \mathrm{min}$. The results of the static three-point bending tests are presented in Table 1, and characteristic bending stressdeformation curves are displayed in Figure 3.

The curves in Figure 3 demonstrate that the composite with PCL-interphase patterning failed in a more ductile manner than the reference. Upon reaching a critical stress level interlaminar-patterned composites failed in multiple steps where each step can be possibly ascribed to interlaminar fracture at a different place within the coupon. Data in Table 1 indicate that essential parameters, like modulus and strength, were less affected by the formation of the interlaminar PCL pattern. While the maximum stress was reached at approximately the same strain, the strain at break was significantly increased.

To investigate the energy absorption properties of the prepared composites at dynamic loads we chose the flatwise Charpy impact test as a dynamic counterpart of the static three-point bend test. The impact tests were performed according to EN ISO 179 on standard $80 \mathrm{~mm}$ long (span length: $62 \mathrm{~mm}$ ), $10 \mathrm{~mm}$ wide specimens at room temperature with a Ceast Resil Impactor Junior pendulum equipped with a $15 \mathrm{~J}$ maximum impact energy hammer. Impact velocity was $3.7 \mathrm{~m} / \mathrm{s}$. The results of the Charpy impact tests are also presented in Table 1.

In the results of the flatwise Charpy impact tests no significant differences can be observed. The results

Table 1. Static and dynamic flexural test results of CF/EP composites with and without a PCL-modified interphase

\begin{tabular}{|l|c|c|c|c|c|c|}
\hline \multicolumn{1}{|c|}{ Composite type } & $\begin{array}{c}\text { Bending } \\
\text { modulus } \\
{[\mathbf{G P a}]}\end{array}$ & $\begin{array}{c}\text { Bending } \\
\text { strength } \\
{[\mathbf{M P a}]}\end{array}$ & $\begin{array}{c}\text { Strain at bending } \\
\text { strength } \\
{[\mathbf{\%}]}\end{array}$ & $\begin{array}{c}\text { Bending stress } \\
\text { at break } \\
{[\mathbf{M P a}]}\end{array}$ & $\begin{array}{c}\text { Strain at } \\
\text { break } \\
{[\mathbf{\%}]}\end{array}$ & $\begin{array}{c}\text { Charpy impact } \\
\text { strength } \\
{\left[\mathbf{k J} / \mathbf{m}^{\mathbf{2}}\right]}\end{array}$ \\
\hline Reference & $57.9 \pm 4.0$ & $738.8 \pm 77.2$ & $1.26 \pm 0.09$ & $197.0 \pm 16.3$ & $1.88 \pm 0.11$ & $76.8 \pm 9.8$ \\
\hline With interlaminar pattern & $59.1 \pm 5.3$ & $692.8 \pm 28.3$ & $1.27 \pm 0.13$ & $194.3 \pm 80.0$ & $2.41 \pm 0.30$ & $78.2 \pm 7.6$ \\
\hline
\end{tabular}


show that the interlaminar pattern did not compromise the integrity of the composites - did not lower impact resistance, but it did not provide any improvement, either. The reason why the patterning did not improve the toughness at high deformation speed is the subject of ongoing studies. This may, however, be linked with the rather small loaded volume of the specimen.

We checked whether interlaminar-patterned thermoplastic PCL can be used as a healing agent by using one of the broken three-point bending test specimens. The broken specimen was placed in a hydraulic press and healed at a hydraulic pressure of 100 bar and a platen temperature of $80^{\circ} \mathrm{C}$ for 15 minutes. Recall that this temperature is just at the $T_{\mathrm{g}}$ of EP and above the $T_{\mathrm{m}}$ of PCL. After pressing, the specimen regained its original shape, the thickness has decreased to $3.1 \mathrm{~mm}$. As further reference, the CF/EP composite without PCL modification might have been considered. The specimen was retested with the same parameters used for the previous three-point bending tests. The recorded bending stress-deformation curves of the first test performed on the neat specimen and of the second test performed on the healed specimen are presented in Figure 4.

The curves in Figure 4 show that the PCL phase worked for healing as anticipated. The large difference between the bending stress-deformation curves before and after healing is due to the fact that the reinforcing layers lost their efficiency being fully fractured in the previous flexure test. Accordingly, the curve after healing is close to that of the neat, unreinforced EP. The scenario may, however, change substantially when subcritical loading (fracturing the reinforcement only partly) is applied on the specimen. In the future our work will mostly focus on unraveling the effects of PCL patterning, PCL modification,

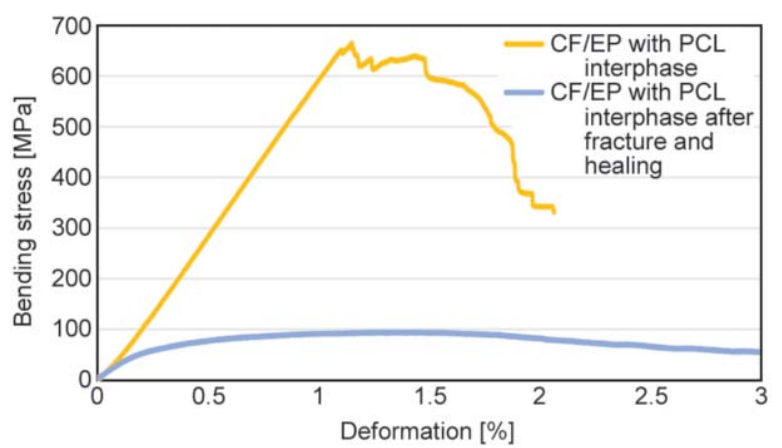

Figure 4. Characteristic bending stress-deformation curves in static three-point bending tests of the CF/EP composites with a PCL-modified interphase before and after healing
RIPS of PCL in various EP resins, in order to exploit the potential of FDM patterning of the surface of different reinforcements in EP resin-based composites.

\section{Conclusions}

This work outlines a novel concept, 3D printing-assisted interphase engineering for polymer composites, and shows its feasibility. Though the concept is general, thereby covering all possible interphase/matrix combinations, we checked it by patterning carbon fiber fabric with thermoplastic poly( $\varepsilon$-caprolactone) (PCL) prior to infiltrating with an amine-curable epoxy (EP) resin. This interphase modification resulted in a pronounced improvement in ductility under static flexure, suggesting that some 'intermittent bonding' of the reinforcement (PCL-rich phase/ EP) develops. No improvement was observed in dynamic flexure tests possibly due to the fact that the Charpy test specimen is rather small, while the patterning is rather rough. The PCL-rich interphase healed well as a remarkable restoration of properties was observed in static flexure after heat treatment of the previously fractured specimen.

\section{Acknowledgements}

This research was supported by The National Research, Development and Innovation Office (OTKA SNN 114547, OTKA K 116070, OTKA FK 124352, NVKP_16-1-2016-0022 and NVKP_16-1-2016-0046). Gábor Szebényi acknowledges the financial support received through János Bolyai Scholarship of the Hungarian Academy of Sciences.

\section{References}

[1] Karger-Kocsis J., Mahmood M., Pegoretti A.: Recent advances in fiber/matrix interphase engineering for polymer composites. Progress in Materials Science, 73, 1$43(2015)$.

https://doi.org/10.1016/j.pmatsci.2015.02.003

[2] Maamar D. B., Ramdane Z.: Characterization of the mechanical behaviour of carbon fiber composite laminate under low velocity impact. Periodica Polytechnica Mechanical Engineering, 60, 142-151 (2015). https://doi.org/10.3311/PPme.8633

[3] Lomov S. V., Molnár K.: Compressibility of carbon fabrics with needleless electrospun PAN nanofibrous interleaves. Express Polymer Letters, 10, 25-35 (2016). https://doi.org/10.3144/expresspolymlett.2016.4

[4] Kostopoulos V., Kotrotsos A., Baltopoulos A., Tsantzalis S., Tsokanas P., Loutas T., Bosman A. W.: Mode II fracture toughening and healing of composites using supramolecular polymer interlayers. Express Polymer Letters, 11, 914-926 (2016).

https://doi.org/10.3144/expresspolymlett.2016.85 
[5] Grishchuk S., Grishchuk O., Weber M., Karger-Kocsis J.: Structure and toughness of polyethersulfone (PESU)modified anhydride-cured tetrafunctional epoxy resin: Effect of PESU molecular mass. Journal of Applied Polymer Science, 123, 1193-1200 (2011).

https://doi.org/10.1002/app.34610

[6] Rotrekl J., Sikora A., Kaprálková L., Dybal J., Kelnar I.: Effect of an organoclay on the reaction-induced phaseseparation in a dynamically asymmetric epoxy/PCL system. Express Polymer Letters, 7, 1012-1019 (2013). https://doi.org/10.3144/expresspolymlett.2013.99

[7] Luo X., Mather P. T.: Triple-shape polymeric composites (TSPCs). Advanced Functional Materials, 20, 2649 2656 (2010).

https://doi.org/10.1002/adfm.201000052
[8] Fejös M., Molnár K., Karger-Kocsis J.: Epoxy/polycaprolactone systems with triple-shape memory effect: Electrospun nanoweb with and without graphene versus co-continuous morphology. Materials, 6, 4489-4504 (2013).

https://doi.org/10.3390/ma6104489

[9] Karger-Kocsis J.: Self-healing properties of epoxy resins with poly( $\varepsilon$-caprolactone) healing agent. Polymer Bulletin, 73, 3081-3093 (2016). https://doi.org/10.1007/s00289-016-1642-2

[10] Atkins A. G.: Intermittent bonding for high toughness/ high strength composites. Journal of Materials Science, 10, 819-832 (1975).

https://doi.org/10.1007/BF01163077 